\title{
Enhanced arsenate removal by novel Fe-La composite (hydr)oxides synthesized via coprecipitation
}

\author{
Wei Zhang a,b,c, Jun Fu ${ }^{\mathrm{d}}$, Gaosheng Zhang ${ }^{\mathrm{a}, \mathrm{b}, *}$, Xiwang Zhang ${ }^{\mathrm{e}}$ \\ ${ }^{a}$ Key Laboratory of Coastal Zone Environmental Processes, Yantai Institute of Coastal Zone Research (YIC), Chinese Academy of Sciences (CAS), 17th Chunhui Road, Yantai, \\ Shandong 264003, China \\ ${ }^{\mathrm{b}}$ Research Center for Coastal Environment Engineering and Technology of Shandong Province, YICCAS, 17th Chunhui Road, Yantai, Shandong 264003, China \\ ${ }^{\mathrm{c}}$ University of Chinese Academy of Sciences, 19th A Yuquan Road, Beijing 100049, China \\ d Sino-Japan Friendship Center for Environmental Protection, Beijing 100029, China \\ ${ }^{\mathrm{e}}$ Department of Chemical Engineering, Monash University, Clayton, Victoria 3800, Australia
}

\section{H I G H L I G H T S}

- Fe-La composite (hydr)oxides were synthesized via coprecipitation method.

- Fe-La composite (hydr)oxides were effective for arsenate removal from water.

- As $(\mathrm{V})$ was removed by both precipitation and sorption under acidic condition.

- As(V) removal was achieved by adsorption under alkaline condition.

\section{A R T I C L E I N F O}

\section{Article history:}

Received 8 February 2014

Received in revised form 10 April 2014

Accepted 12 April 2014

Available online 2 May 2014

\section{Keywords:}

Fe-La composite (hydr)oxides

Arsenate

Adsorption

Removal
G R A P H I C A L A B S T R A C T

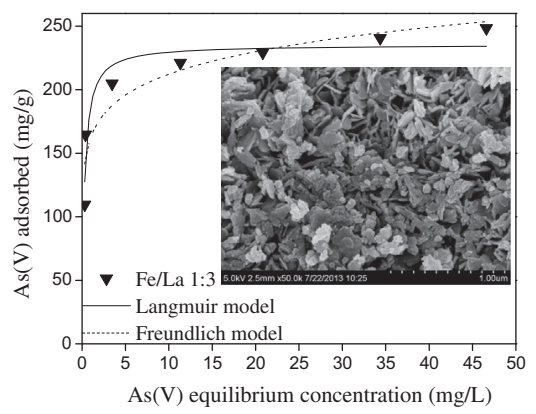

\begin{abstract}
A B S T R A C T
Arsenic exists ubiquitously in the environment and has been proved to be of great harm to human health. In this study, a series of Fe-La composite (hydr)oxides were synthesized via a facile coprecipitation for effective $\mathrm{As}(\mathrm{V})$ removal from aqueous solution. A variety of techniques including BET surface area measurement, powder XRD, SEM, and XPS were employed to characterize the synthetic Fe-La composite (hydr)oxides. Fe-La composite (hydr)oxides grains were formed via aggregation of primary nanoparticles. With an increase in La content, the specific surface area of Fe-La composite (hydr)oxides decreased, but the pore diameter, the pore volume and the grain size of Fe-La composite (hydr)oxides increased gradually. Rapid $\mathrm{As}(\mathrm{V})$ adsorption on the synthesized composite oxides was achieved and the adsorption was well fitted by the pseudo-second-order equation. The adsorption isotherms could be well described by Langmuir equation and the maximal adsorption capacity of Fe-La composite (hydr)oxides can reach $368 \mathrm{mg} / \mathrm{g}$. The $\mathrm{As}(\mathrm{V})$ removal was $\mathrm{pH}$-dependent and decreased with an increase in $\mathrm{pH}$ value, especially in alkaline condition. Under acidic and neutral conditions, $\mathrm{As}(\mathrm{V})$ removal was mainly achieved by both precipitation and adsorption. By contrast, adsorption is the only mechanism for $\mathrm{As}(\mathrm{V})$ removal in alkaline condition. The results indicate that the Fe-La composite (hydr)oxides could be potentially attractive adsorbents for $\mathrm{As}(\mathrm{V})$ removal.
\end{abstract}

(c) 2014 Elsevier B.V. All rights reserved.

\footnotetext{
* Corresponding author at: Key Laboratory of Coastal Zone Environmental Processes, Yantai Institute of Coastal Zone Research (YIC), Chinese Academy of Sciences (CAS), 17th Chunhui Road, Yantai, Shandong 264003, China. Fax: +86 0535 2109139.

E-mail address: gszhang@yic.ac.cn (G. Zhang).
}

\section{Introduction}

Arsenic, a well-known element, is ubiquitous in the environment and of worldwide serious concern due to its high toxicity and carcinogenicity [1-4]. Arsenic is generally introduced into 
the aquatic environment through both natural process and anthropogenic activity. The former includes weathering reactions, dissolution of minerals and biological activity while the latter mainly contains mining, agriculture and manufacturing [1,3,4]. Arsenic pollution is one of the most serious environmental problems. Long term uptake of arsenic contaminated drinking water can cause gastrointestinal, skin, liver and nerve tissue injures [5]. To minimize these health risks, a strict guideline limit of $10 \mu \mathrm{g} / \mathrm{l}$ set by the World Health Organization (WHO) has been adopted as the drinking water standard by many countries [6].

Various treatment technologies for arsenic removal have been investigated in recent years including precipitation, coprecipitation, ion-exchange, adsorption, ultra filtration, and reverse osmosis [5]. Among these, adsorption technique is considered one of the most popular and practical methods for arsenic removal due to its high efficiency, low cost and reusable characteristics [7,8]. More and more attentions have been paid on the development of high performance adsorbents including natural and synthetic materials to control the arsenic pollution [9]. Iron (hydr)oxides are regarded as promising adsorbent materials as they have strong affinities toward inorganic arsenic species which results in high selectivity to arsenic in the sorption processes [10-12]. Moreover, they are low-cost and environmental friendly. Most recently, increasing efforts have been devoted to the synthesis of novel composite adsorbents containing iron oxides, including Fe-Ce [13], Fe-Mn [14], Fe-Al [15], Fe-Zr [16], Fe-Cu [17], Fe-Ti [18]. These composites exhibited high adsorption capacity for arsenic removal than their individual components.

Previous study showed that Lanthanum (hydr)oxides had good performance in arsenate removal from water over a wide $\mathrm{pH}$ range [19]. However, it is not so economical to use pure Lanthanum (hydr)oxides as sorbent, due to its relatively high cost (The current price of powder Lanthanum oxide ( $>99 \%$ ) is US $\$ 8000-20,000 /$ Ton). To reduce cost, some composite adsorbents containing Lanthanum (hydr)oxides have therefore been developed. For examples, Wasay et al. developed lanthanum-impregnated silica gel to remove arsenate ions [20]. Jang et al. synthesized a Lanthanum functionalized mesoporous media to adsorb arsenate from water [21]. Pu et al. prepared a lanthanum-loaded zeolite adsorbent for arsenate removal [22]. Guo et al. demonstrated that a La-containing LDH adsorbent was efficient in removing arsenic from aqueous solutions [23].

However, up to now, no report is available in the literature on arsenate removal by Fe-La composite (hydr)oxides although they are maybe an excellent adsorbent given that both Fe and La oxides have good adsorption capacity for arsenate. Investigation on the Fe-La composite (hydr)oxides may offer new insights to the development of high performance adsorbents for arsenate removal. In addition, the price of iron oxide (US $\$ 500-1000 /$ Ton) is much lower than that of Lanthanum oxide. Their combination would remarkably lower the adsorbent cost. Therefore, a facile chemical precipitation method was developed to synthesize Fe-La composite (hydr)oxides at ambient temperature in this study. The main objectives of this research were (1) to synthesize Fe-La composite (hydr)oxides with different Fe/La molar ratios; (2) to characterize the synthesized Fe-La composite (hydr)oxides with a variety of techniques; (3) to evaluate their arsenate adsorption capacity; and finally (4) to investigate the mechanism for arsenate removal.

\section{Materials and methods}

\subsection{Materials}

Analytic grade chemicals including $\mathrm{FeCl}_{3} \cdot 6 \mathrm{H}_{2} \mathrm{O}, \mathrm{LaCl}_{3} \cdot n \mathrm{H}_{2} \mathrm{O}$ and $\mathrm{NaOH}$ were purchased from Sinopharm Chemical Reagent Beijing
Co. (Beijing, China). As(V) stock solutions were prepared with deionized water using $\mathrm{Na}_{2} \mathrm{HAsO}_{4} \cdot 7 \mathrm{H}_{2} \mathrm{O}$, respectively. $\mathrm{As}(\mathrm{V})$ working solutions were freshly prepared by diluting $\mathrm{As}(\mathrm{V})$ solutions with deionized water. The concentrations of arsenic species were always given as elemental arsenic concentration in this study.

\subsection{Adsorbent preparation}

A series of Fe-La composite (hydr)oxides were synthesized under different $\mathrm{Fe} / \mathrm{La}$ molar ratios at room temperature. Typically, a certain amount of $\mathrm{FeCl}_{3} \cdot 6 \mathrm{H}_{2} \mathrm{O}$ and $\mathrm{LaCl}_{3} \cdot n \mathrm{H}_{2} \mathrm{O}$ were dissolved in $400 \mathrm{ml}$ deionized water. The $\mathrm{Fe} / \mathrm{La}$ molar ratio was adjusted to the predetermined value via changing the amount of $\mathrm{FeCl}_{3} \cdot 6 \mathrm{H}_{2} \mathrm{O}$ or $\mathrm{LaCl}_{3} \cdot n \mathrm{H}_{2} \mathrm{O}$ added. Under vigorous stirring, sodium hydroxide solution $(2 \mathrm{~mol} / \mathrm{l})$ was added dropwise to raise the solution $\mathrm{pH}$ to around 8.5. After addition, the formed suspension was continuously stirred for $1 \mathrm{~h}$, aged at room temperature for $4 \mathrm{~h}$ and then washed several times with deionized water. The suspension was then filtrated and dried at $55^{\circ} \mathrm{C}$ for $24 \mathrm{~h}$. The dried materials were crushed and stored in a desiccator for use. The obtained material appeared in the form of fine powder, which were named as Fe/La $X: Y(X: Y=1: 0,3: 1,1: 1,1: 3$ and $0: 1 . X: Y$ means the molar ratio of $\mathrm{FeCl}_{3} \cdot 6 \mathrm{H}_{2} \mathrm{O}$ and $\left.\mathrm{LaCl}_{3} \cdot n \mathrm{H}_{2} \mathrm{O}\right)$.

\subsection{Adsorbent characterization}

The morphology of the particles was characterized by a field scanning electron microscope (FESEM) (Hitachi S-4800, Japan). $\mathrm{X}$-ray diffraction (XRD) analysis was carried out on a D/Max-3A diffractometer (Rigaku Co., Japan) using Ni-filtered copper $\mathrm{Ka}_{1}$ radiation. The specific surface area was measured via nitrogen adsorption using BET method with a Micromeritics ASAP 2000 surface area analyzer (Micromeritics Co., USA).

The point of zero charge (pzc) of the Fe-La composite (hydr)oxides was determined according to the slightly modified method described by Kinniburgh et al. [24]. Fe-La composite (hydr)oxides powders were first suspended in $0.01 \mathrm{M} \mathrm{NaNO}_{3}$ for $24 \mathrm{~h}$, which can slow down the $\mathrm{pH}$ change with time. Suspension samples of $50 \mathrm{ml}$ were then adjusted to various $\mathrm{pH}$ values with $\mathrm{NaOH}$ or $\mathrm{HNO}_{3}$ solution. After agitation for $60 \mathrm{~min}$ for equilibrium, the $\mathrm{pH}$ of solution was measured which is named initial $\mathrm{pH}$. Subsequently $1 \mathrm{~g}$ of $\mathrm{NaNO}_{3}$ was added to each suspension samples to bring final electrolyte concentration to $0.25 \mathrm{M}$. After three more hours, the final $\mathrm{pH}$ was measured. The results, plotted as $\mathrm{pH}_{f}-\mathrm{pH}_{i}$ (final $\mathrm{pH}$-initial $\mathrm{pH}$ ) against final $\mathrm{pH}$, yielded the $\mathrm{pzc}$ as the $\mathrm{pH}$ where $\mathrm{pH}_{f}-\mathrm{pH}_{i}=0$.

FTIR spectra were collected on a Nicolet IS10 FTIR spectrophotometer (Thermo scientific, USA) using a transmission model. Samples for FTIR determination were ground with spectral grade $\mathrm{KBr}$ in an agate mortar. IR spectra of arsenate adsorbed onto $\mathrm{Fe}-\mathrm{La}$ composite (hydr)oxides were obtained from dry samples in $\mathrm{KBr}$ pellets corresponding to $5 \mathrm{mg}$ of sample in approximately $200 \mathrm{mg}$ of $\mathrm{KBr}$. All IR measurements were carried out at room temperature.

X-ray photoelectron spectra (XPS) were collected on an ESCALab-220i-XL spectrometer with a monochromatic Al Ka X-ray source $(1486.6 \mathrm{eV}) . \mathrm{C} 1 \mathrm{~s}$ peaks were used as an inner standard calibration peak at $284.7 \mathrm{eV}$. For wide-scan spectra, an energy range of $0-1100 \mathrm{eV}$ was used with pass energy $80 \mathrm{eV}$ and step size $1 \mathrm{eV}$. The high-resolution scans were conducted according to the peak being examined with pass energy $40 \mathrm{eV}$ and step size $0.05 \mathrm{eV}$. The XPS results were collected in binding energy forms and fitted using a nonlinear least-squares curve-fitting program (XPSPEAK41 Software). 


\subsection{Batch adsorption tests}

\subsubsection{Adsorption kinetics}

The kinetics experiments were carried out at room temperature $\left(25 \pm 1^{\circ} \mathrm{C}\right)$. To prepare a series of arsenate solutions with different initial concentrations, predetermined amount of arsenate stock solution and $\mathrm{NaNO}_{3}$ were added in a $1000-\mathrm{ml}$ glass vessel and then diluted to $500 \mathrm{ml}$ with DI water. The initial arsenate concentration was $15 \mathrm{mg} / \mathrm{l}, 20 \mathrm{mg} / \mathrm{l}, 30 \mathrm{mg} / \mathrm{l}$ and $50 \mathrm{mg} / \mathrm{l}$, respectively. The ionic strength of the solutions was $0.01 \mathrm{M}$. After the solution $\mathrm{pH}$ was adjusted to $7.0 \pm 0.1$ by adding $0.1 \mathrm{M} \mathrm{HNO}_{3}$ and/or $\mathrm{NaOH}, 0.1 \mathrm{~g}$ of Fe-La composite (hydr)oxides were added to obtain a $0.2 \mathrm{~g} / \mathrm{l}$ suspension. The suspension was mixed with a magnetic stirrer at an agitation speed of $170 \mathrm{rpm}$, and the $\mathrm{pH}$ was maintained at $7.0 \pm 0.1$ throughout the experiment by addition of dilute acid and/or base solutions. Approximately $5-\mathrm{ml}$ aliquots were taken from the vessel at predetermined times. The samples were immediately filtered through a $0.45-\mu \mathrm{m}$ membrane filter. The concentrations of residual arsenate were determined using an inductively coupled plasma atomic emission spectroscopy (ICP-OES).

\subsubsection{Effect of solution $\mathrm{pH}$}

The influence of solution $\mathrm{pH}$ on the arsenate adsorption was investigated by adding $10 \mathrm{mg}$ of $\mathrm{Fe}$-La composite (hydr)oxides into $100-\mathrm{ml}$ plastic vessels, containing $50 \mathrm{ml}$ of arsenate solution. Initial arsenate concentration was $15 \mathrm{mg} / \mathrm{l}, 20 \mathrm{mg} / \mathrm{l}, 30 \mathrm{mg} / \mathrm{l}$ and $50 \mathrm{mg} / \mathrm{l}$, respectively. The $\mathrm{pH}$ of the solutions was adjusted every $4 \mathrm{~h}$ with dilute $\mathrm{HNO}_{3}$ or/and $\mathrm{NaOH}$ solution to designated values in the range 3-11 during the shaking process. The equilibrium $\mathrm{pH}$ was measured and the supernatant was filtered through a $0.45-\mu \mathrm{m}$ membrane for arsenate measurement after the solutions were mixed for $36 \mathrm{~h}$. In addition, to evaluate the leaching of Fe and La from the adsorbent at different $\mathrm{pH}$, the Fe and La concentrations in the supernatant solutions were also measured by ICP-OES.

\subsubsection{Adsorption isotherms}

The arsenate adsorption isotherm was determined using batch tests at $\mathrm{pH} 7.0 \pm 0.1$. The $\mathrm{pH}$ of suspensions was adjusted with $0.1 \mathrm{M}$ of $\mathrm{NaOH}$ and $\mathrm{HNO}_{3}$ during the experiment. Initial arsenate concentration varied from $2 \mathrm{mg} / \mathrm{l}$ to $100 \mathrm{mg} / \mathrm{l}$. In each test, $10 \mathrm{mg}$ of Fe-La composite (hydr)oxides were loaded in a $100-\mathrm{ml}$ plastic vessel containing $50 \mathrm{ml}$ arsenate solution of predetermined concentration. Ionic strength of the solution was adjusted to $0.01 \mathrm{M}$ with $\mathrm{NaNO}_{3}$. The vessels were shaken on an orbit shaker at $170 \mathrm{rpm}$ for $36 \mathrm{~h}$ at $25 \pm 1{ }^{\circ} \mathrm{C}$. Then, all samples were filtered by a $0.45-\mu \mathrm{m}$ membrane filter and analyzed for arsenate. The quantity of adsorbed arsenate was calculated by the difference of the initial and residual amounts of arsenate in solution divided by the weight of the adsorbent. Additionally, in order to study the influence of temperature on arsenate adsorption, batch tests were also conducted at other two temperatures of $15 \pm 1^{\circ} \mathrm{C}$ and $35 \pm 1^{\circ} \mathrm{C}$.

\subsubsection{Regeneration and reusability of the Fe/La 1:1 composite (hydr)oxide}

Four cycles of adsorption and desorption were carried out to assess the reusability of the Fe/La $1: 1$ composite (hydr)oxide. For the adsorption tests, $400 \mathrm{mg}$ of the Fe/La 1:1 composite (hydr)oxide was introduced into 21 arsenate solution of $33 \mathrm{mg} / \mathrm{l}$. The solution was stirred continuously for $20 \mathrm{~h}$ at $170 \mathrm{rpm}$ and $25 \pm 1{ }^{\circ} \mathrm{C}$. The $\mathrm{pH}$ of the solution was maintained at $9.0 \pm 0.1$ during adsorption process. Then the sorbent was separated by filtration and was used for desorption tests after drying at $55^{\circ} \mathrm{C}$ for $1 \mathrm{~d}$. For the desorption tests, the arsenate-containing Fe/La 1:1 composite (hydr)oxide was added into $100 \mathrm{ml} \mathrm{NaOH}$ solution of $0.5 \mathrm{~mol} / \mathrm{l}$. The mixture was stirred for $6 \mathrm{~h}$ and then separated from the $\mathrm{NaOH}$ solution. After washing and drying, the sorbent was to be used in the next adsorption-desorption cycle.

\subsection{Analytical methods}

Arsenate concentration was determined by an ICP-OES (Optima 7100 DV, Perkin Elmer Co., USA). Prior to analysis, the aqueous samples were acidified with concentrated $\mathrm{HCl}$ in an amount of $1 \%$ and stored in acid-washed glass vessels. All samples were analyzed within $24 \mathrm{~h}$ after collection.

\section{Results and discussion}

\subsection{Characterization of Fe-La composite (hydr)oxides}

\subsubsection{Scanning electron microscopy}

The morphology of Fe-La composite (hydr)oxides was examined by SEM. As shown in Fig. 1, the pure Fe (hydr)oxide grains were aggregates formed compactly by ball-like nanoparticles of 20-50 nm. By contrast, the pure La (hydr)oxide grains were aggregates of nanoflakes of $100-200 \mathrm{~nm}$. With decreasing Fe/La ratio, the grain size of the Fe-La composite (hydr)oxides increased and their structures became loose. At low Fe/La ratio, their morphologies and structures look like those of pure La (hydr)oxide.

\subsubsection{Specific surface area}

The $\mathrm{N}_{2}$ adsorption and desorption isotherms of the Fe-La composite (hydr)oxides were shown in Fig. 2. The adsorption and desorption isotherms of Fe-La composite (hydr)oxides at ratio of 3:1 is type I according to the IUPAC classification while their isotherms are type IV at ratio of $1: 1,1: 3$ and $0: 1$. Fe/La 3:1 material was microporous. And other three materials were possibly mesoporous, as they all demonstrated a hysteresis loop for the desorption isotherm [25]. The adsorption isotherms of Fe/La 1:3 and Fe/La 0:1 did not present a plateau at high $p / p_{0}$ values, indicating that these pores might be produced by aggregation of platelet-like particles.

The data of specific surface area, average pore diameter, and average pore volume of $\mathrm{Fe}$-La composite (hydr)oxides were listed in Table 1. It can be seen that with an increase in La content, the specific surface area of Fe-La composite (hydr)oxides decreased. On the contrary, the pore diameter and the pore volume increased gradually. For the Fe/La 3:1 (hydr)oxide, the surface area was as high as $224.5 \mathrm{~m}^{2} / \mathrm{g}$, while the surface area of the pure La (hydr)oxide was only $46.7 \mathrm{~m}^{2} / \mathrm{g}$. This reduce might be ascribed to an increase of particle size and change in particle shape from ball-like nanoparticle to nanoflake as La content increasing in the composite, which was observed by the SEM. Generally, sorbent with a smaller particle size possesses a larger surface area and ball-like particle has the largest specific surface area.

\subsubsection{X-ray diffraction}

Fig. 3 shows the XRD patterns of the synthesized Fe-La composite (hydr)oxides. The oxide at an Fe/La molar ratio of 1:0, namely the pure Fe (hydr)oxide, has two broad peaks at approximately $35.4^{\circ}$ and $62.2^{\circ}$, which are attributed to d spacing of 0.254 and $0.149 \mathrm{~nm}$ of poorly ordered two-line ferrihydrite [26]. This indicates that the Fe/La 1:0 was amorphous and consisted of two-line ferrihydrite. The oxide with an Fe/La molar ratio of $0: 1$, namely the pure La (hydr)oxide, showed some sharp and symmetric reflections for (100), (101), (201) and (300) planes and broad asymmetric peaks for (112), (311) and (410) planes, which were similar to the XRD pattern of $\mathrm{La}(\mathrm{OH})_{3}$ (JCPDS 36-1481) [27]. For Fe-La composite (hydr)oxides, with an increase in La content, the peaks of two-line ferrihydrite weakened and eventually disappeared, meanwhile the peaks of $\mathrm{La}(\mathrm{OH})_{3}$ appeared and increased. 

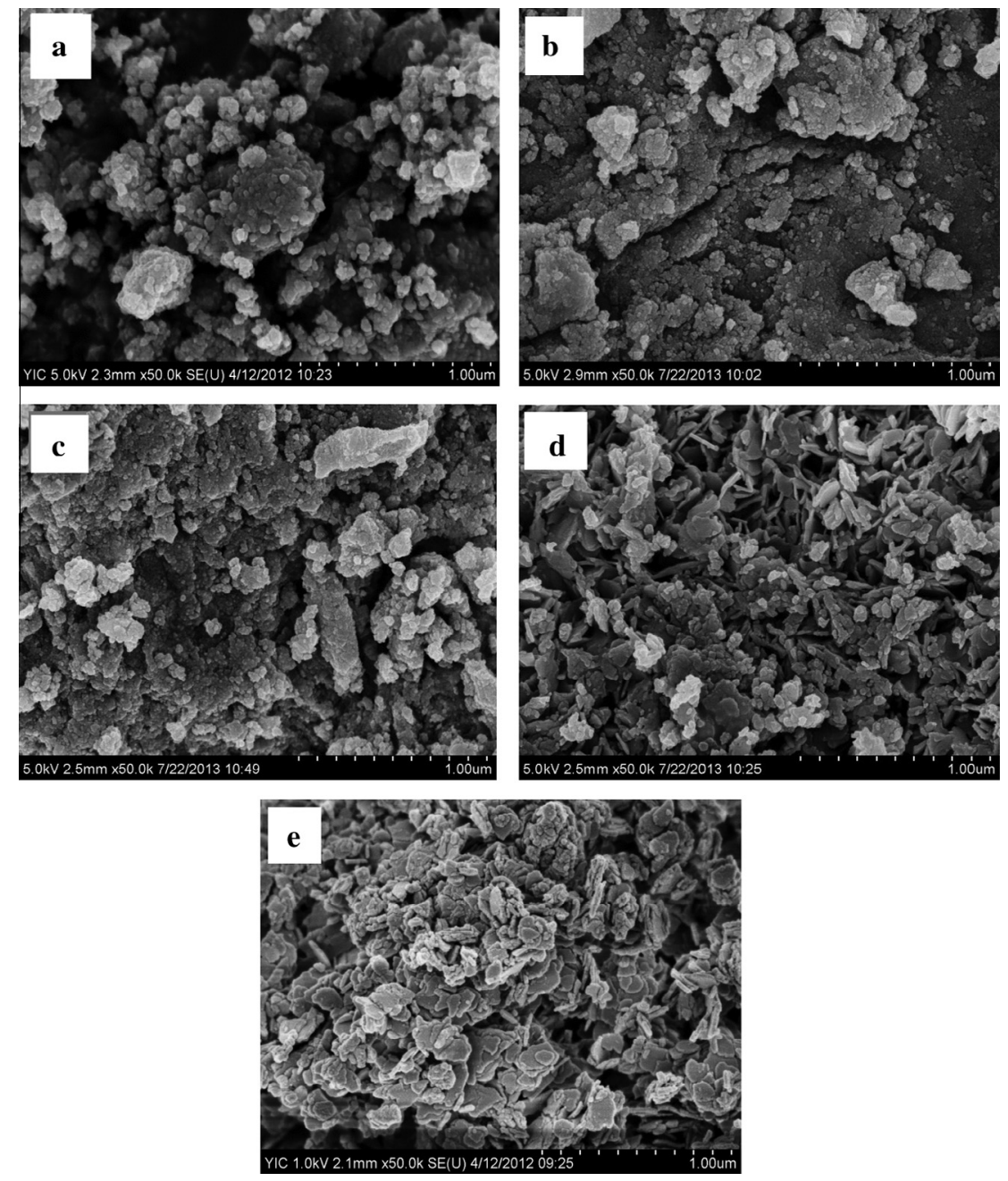

Fig. 1. SEM micrographs of Fe-La composite (hydr)oxides particles. (a) Fe/La 1:0, (b) Fe/La 3:1, (c) Fe/La 1:1, (d) Fe/La 1:3 and (e) Fe/La 0:1.

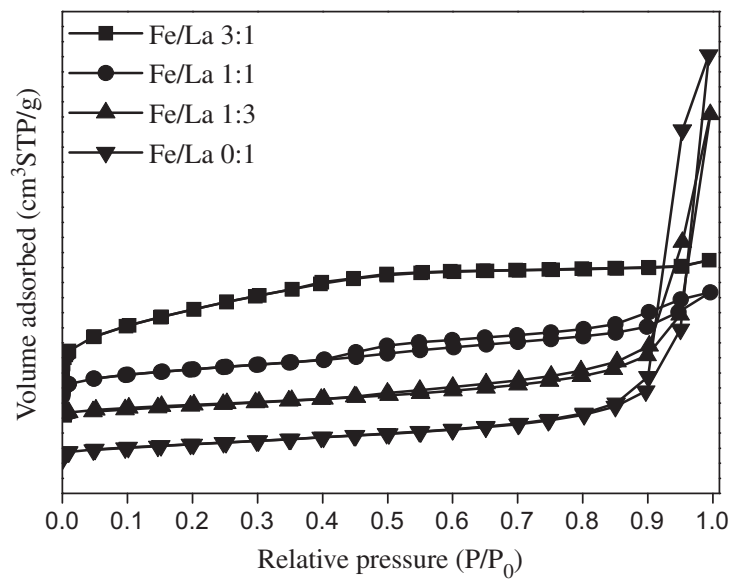

Fig. 2. $\mathrm{N}_{2}$ adsorption/desorption isotherms of the Fe-La composite (hydr)oxides with different molar ratios.

In addition, no new peaks were formed, indicating that (hydr)oxides were a kind of mixture.

\subsubsection{Point of zero charge ( $p z c$ )}

The pzc values of Fe-La composite (hydr)oxides were shown in Fig. 4. The pzc of $3: 1,1: 1,1: 3$ and $0: 1$ Fe-La composite (hydr)oxides were 7.4, 7.8, 8.3 and 9.3, respectively. Clearly, the pzc value raised as La content increased in these (hydr)oxides. The obtained pzc values were consistent with literatures. Previous studies showed the pzc of pure ferrihydrite was pH 7-9 [15] and that of $\mathrm{La}(\mathrm{OH})_{3}$ was about $\mathrm{pH} 10.1$ [19].

\subsection{Batch adsorption experiments}

\subsubsection{Adsorption capacity of Fe-La composite (hydr)oxides}

The adsorption isotherms for $\mathrm{As}(\mathrm{V})$ were presented in Fig. 5. Obviously, the Fe-La composite (hydr)oxides had a high adsorption capacity for As(V). Both Langmuir and Freundlich models [28,29] were employed to describe the adsorption isotherms obtained in the figure. The two equations can be expressed as follows:

$q_{e}=\frac{q_{\max } K_{L} C_{e}}{1+K_{L} C_{e}}$

$q_{e}=K_{F} C_{e}^{n}$

where $q_{e}$ and $q_{\max }$ represent the amount of equilibrium adsorption capacity and the maximum adsorption capacity $(\mathrm{mg} / \mathrm{g})$, respectively; $K_{L}(1 / \mathrm{mg})$ is the Langmuir coefficient; $C_{e}$ is the equilibrium solution concentration $(\mathrm{mg} / \mathrm{l}) ; K_{F}$ is roughly an indicator of the adsorption capacity and $n$ is an empirical parameter; $n$ is the heterogeneity factor, which has a lower value for more heterogeneous surfaces. 
Table 1

BET specific surface area and porosity measurements of Fe-La composite (hydr)oxides.

\begin{tabular}{|c|c|c|c|}
\hline Adsorbent & Specific surface area $\left(\mathrm{m}^{2} / \mathrm{g}\right)$ & Average pore diameter $(\AA)$ & Average pore volume $\left(\mathrm{cm}^{3} / \mathrm{g}\right)$ \\
\hline $\mathrm{Fe} / \mathrm{La} 3: 1$ & 224.5 & 26.1 & 0.146 \\
\hline Fe/La $1: 1$ & 99.3 & 74.0 & 0.184 \\
\hline $\mathrm{Fe} / \mathrm{La} 1: 3$ & 54.8 & 227.7 & 0.312 \\
\hline $\mathrm{Fe} / \mathrm{La} 0: 1$ & 46.7 & 359.4 & 0.420 \\
\hline
\end{tabular}

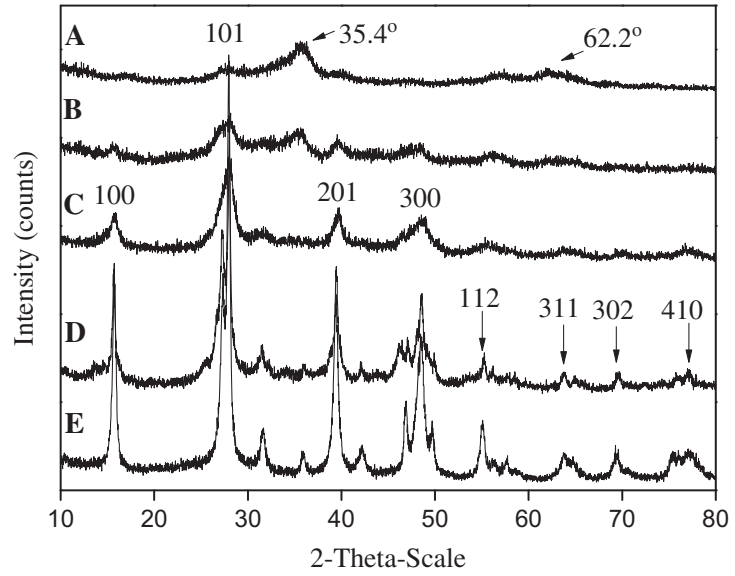

Fig. 3. XRD patterns of Fe-La composite (hydr)oxides. (A) Fe/La 1:0, (B) Fe/La 3:1, (C) Fe/La 1:1, (D) Fe/La 1:3 and (E) Fe/La 0:1.

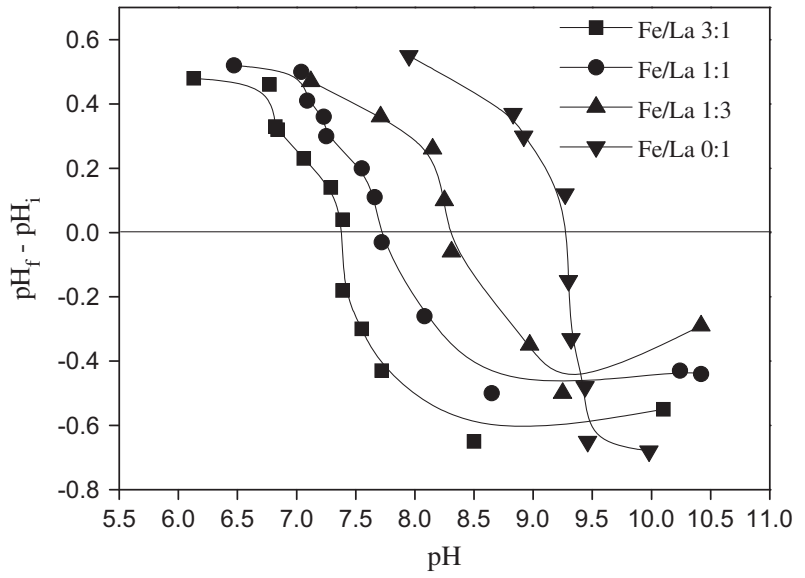

Fig. 4. Points of zero charge (pzc) determination for Fe-La composite (hydr)oxides

The adsorption constants obtained from the isotherms were listed in Table 2. It was seen that the equilibrium data for the adsorption of arsenate onto these Fe-La composite (hydr)oxides could be better described by the Langmuir isotherm model than Freundlich model. As $(\mathrm{V})$ Langmuir adsorption capacities on $3: 1$, $1: 1,1: 3$ and $0: 1 \mathrm{Fe}-\mathrm{La}$ composite (hydr)oxides were $116 \mathrm{mg} / \mathrm{g}$, $166 \mathrm{mg} / \mathrm{g}, 235 \mathrm{mg} / \mathrm{g}$ and $368 \mathrm{mg} / \mathrm{g}$, respectively, indicating that higher La content leads to higher arsenate adsorption ability.

Table 3 shows the comparison results of the maximum adsorption capacities of various adsorbents for $\mathrm{As}(\mathrm{V})$. It is found that the prepared $\mathrm{Fe}$-La composite (hydr)oxides outperform many other adsorbents, which make them promising for $\mathrm{As}(\mathrm{V})$ removal from aqueous solutions. In addition, our recent studies show that the Fe-La composite (hydr)oxides are far effective for As(III) removal than the pure La (hydr)oxide. This indicates that the Fe-La composite (hydr)oxides can be used to remove $\mathrm{As}(\mathrm{V})$ and $\mathrm{As}(\mathrm{III})$ simultaneously. The details about As(III) removal will be demonstrated in another paper.

\subsubsection{Arsenate adsorption thermodynamics of Fe/La 1:1 composite (hydr)oxide}

The effect of three different temperatures (288, 298 and $308 \mathrm{~K})$ on $\mathrm{As}(\mathrm{V})$ adsorption by the Fe/La 1:1 composite (hydr)oxide was investigated at $\mathrm{pH} 7.0 \pm 0.1$ and the results were presented in SI (Supplementary Information) Fig. 1A. It was found that the adsorption capacity increased with increasing temperature, which indicated macroscopically that the adsorption process was endothermic in nature.

The thermodynamic parameters such as change in standard free energy $\left(\Delta G^{\theta}\right)$, enthalpy $\left(\Delta H^{\theta}\right)$ and entropy $\left(\Delta S^{\theta}\right)$ were determined by using the following equations [39]:

$$
\begin{aligned}
& \ln K_{c}=\frac{\Delta S^{\theta}}{R}-\frac{\Delta H^{\theta}}{R T} \\
& \Delta G^{\theta}=\Delta H^{\theta}-T \Delta S^{\theta}
\end{aligned}
$$

where $R\left(8.314 \mathrm{~J} \mathrm{~mol}^{-1} \mathrm{~K}^{-1}\right)$ is the gas constant, $T(\mathrm{~K})$ the absolute temperature and $K_{c}\left(\mathrm{ml} \mathrm{g}^{-1}\right)$ is the standard thermodynamic equilibrium constant defined by $q_{e} / C_{e}$. By plotting a graph of $\ln K_{c}$ versus $T^{-1}$ (SI Fig. 1B) the values $\Delta H^{\theta}$ and $\Delta S^{\theta}$ can be estimated from the slope and intercept [40]. SI Table 1 shows the negative values of $\Delta G^{\theta}$ and positive $\Delta H^{\theta}$ obtained indicated that the $\mathrm{As}(\mathrm{V})$ adsorption process is a spontaneous and an endothermic [41]. The $\Delta H^{\theta}$ value is found to be over than $40 \mathrm{~kJ} \mathrm{~mol}^{-1}$ which indicates the adsorption of $\mathrm{As}(\mathrm{V})$ is chemisorption [42]. The decrease in $\Delta G^{\theta}$ with the increase of temperature indicated more efficient adsorption at higher temperature. The positive value of $\Delta S^{\theta}$ suggests increased randomness at the solid/solution interface occur in the internal structure of the $\mathrm{As}(\mathrm{V})$ adsorption onto the Fe/La 1:1 composite (hydr)oxide [41].

\subsubsection{Kinetics of arsenate adsorption by $\mathrm{Fe}-\mathrm{La}$ composite (hydr)oxides}

Fig. 6 shows the change of adsorbed arsenate as a function of contact time. It is obvious that the adsorption process can be divided into two steps. In the first step, the adsorption rate is fast, and over $80 \%$ of the equilibrium adsorption capacity is achieved within $4 \mathrm{~h}$. In the second step, the adsorption slows down and about $24 \mathrm{~h}$ are required to reach the adsorption equilibrium. Therefore, for all batch experiments, the adsorption time was set at $36 \mathrm{~h}$, to ensure complete adsorption. Adsorption caused by electrostatic processes is usually very rapid, on the order of seconds [10]. As the adsorption of arsenate on the Fe-La composite (hydr)oxides is on the order of hours, it can be concluded that specific adsorption might occur.

Kinetic data analysis for arsenate adsorption onto Fe-La composite (hydr)oxides was studied with the pseudo-first-order model [43] and the pseudo-second-order model [44]. The mathematical representations of the models are given in:

$\frac{d q_{t}}{d t}=k_{1}\left(q_{e}-q_{t}\right)$

$\frac{d q_{t}}{d t}=k_{2}\left(q_{e}-q_{t}\right)^{2}$

where $q_{e}$ and $q_{t}$ are the adsorption capacities $(\mathrm{mg} / \mathrm{g}$ ) of the adsorbent at equilibrium and at any time $t(\mathrm{~h})$, respectively; and $k_{1}\left(\mathrm{~h}^{-1}\right)$ and $k_{2}(\mathrm{~g} / \mathrm{mg} \mathrm{h})$ are the related adsorption rate constants. 

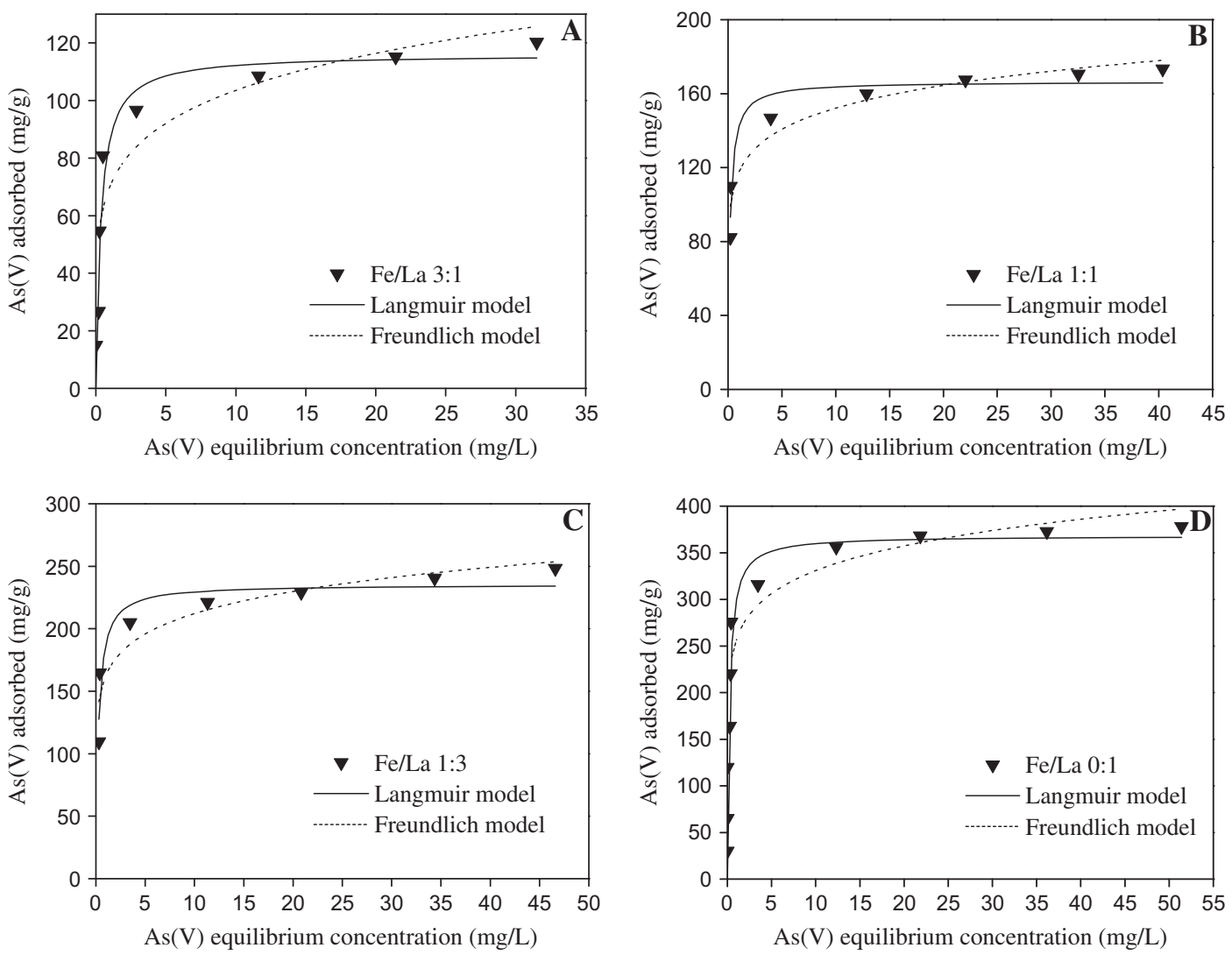

Fig. 5. Isotherms for As(V) adsorption by Fe-La composite (hydr)oxides. (A) Fe/La 3:1, (B) Fe/La 1:1, (C) Fe/La 1:3 and (D) Fe/La 0:1.

Table 2

Langmuir and Freundlich isotherm parameters for $\mathrm{As}(\mathrm{V})$ adsorption onto Fe-La composite (hydr)oxides at pH 7.0 \pm 0.1 .

\begin{tabular}{|c|c|c|c|c|c|c|}
\hline \multirow[t]{2}{*}{ Adsorbent species } & \multicolumn{3}{|c|}{ Langmuir model } & \multicolumn{3}{|c|}{ Freundlich model } \\
\hline & $q_{\max }(\mathrm{mg} / \mathrm{g})$ & $K_{L}(\mathrm{l} / \mathrm{mg})$ & $R^{2}$ & $K_{F}(\mathrm{mg} / \mathrm{g})$ & $1 / n$ & $R^{2}$ \\
\hline $\mathrm{Fe} / \mathrm{La} 3: 1$ & 116 & 2.883 & 0.918 & 70.1 & 0.169 & 0.793 \\
\hline $\mathrm{Fe} / \mathrm{La} 1: 1$ & 166.5 & 5.753 & 0.91 & 117.5 & 0.112 & 0.906 \\
\hline $\mathrm{Fe} / \mathrm{La} 1: 3$ & 235.4 & 3.875 & 0.885 & 162.5 & 0.116 & 0.856 \\
\hline Fe/La 0:1 & 368.1 & 4.272 & 0.913 & 256.5 & 0.111 & 0.837 \\
\hline
\end{tabular}

Table 3

Comparison of maximum $\mathrm{As}(\mathrm{V})$ adsorption capacities for different adsorbents.

\begin{tabular}{llll}
\hline Sorbent material & $\mathrm{pH}$ & $\begin{array}{l}\text { Langmuir } \\
\text { capacity }(\mathrm{mg} / \mathrm{g})\end{array}$ & Reference \\
\hline $\mathrm{Fe} / \mathrm{La} 3: 1$ & 7 & 116 & Present study \\
$\mathrm{Fe} / \mathrm{La} 1: 1$ & 7 & 166 & Present study \\
$\mathrm{Fe} / \mathrm{La} 1: 3$ & 7 & 235 & Present study \\
$\mathrm{Fe} / \mathrm{La} 0: 1$ & 7 & 368 & Present study \\
$\mathrm{Fe}-\mathrm{Mn}$ binary oxide & 5 & 69.8 & {$[14]$} \\
$\mathrm{Cu} / \mathrm{Mg} / \mathrm{Fe} /$ La-LDH & 6 & 43.5 & {$[23]$} \\
$\mathrm{La}-\mathrm{Ce}$ binary hydroxide & 7 & 89.9 & {$[22]$} \\
La functionalized mesoporous media & 7.2 & 123.7 & {$[21]$} \\
Lanthanum carbonate & 4 & 187 & {$[30]$} \\
$\mathrm{Fe}-\mathrm{Zr}$ binary oxide & 7 & 46.1 & {$[31]$} \\
$\mathrm{Al} \mathrm{O}_{3} / \mathrm{Fe}(\mathrm{OH})_{3}$ & 7 & 36.7 & {$[32]$} \\
$\mathrm{NHITO}$ & 7 & 14.3 & {$[33]$} \\
Crystalline hydrous ferric oxide & 7 & 25 & {$[34]$} \\
Nano-TiO $_{2}$ & 7 & 37.5 & {$[35,36]$} \\
Hydrous stannic oxide & 7 & 4.3 & {$[37]$} \\
Akaganeite nanocrystal & 7.5 & 134.1 & {$[38]$} \\
\hline
\end{tabular}

The rate constants obtained from the pseudo-first-order and the pseudo-second-order models are summarized in Table 4. For different adsorbent with same initial adsorbate concentration, a larger adsorption rate constant usually represents a quicker adsorption. However, for the Fe-La composite (hydr)oxide systems, the initial arsenate concentrations varied significantly. Thus, the change of overall adsorption rate (given by the rate constants) was irregular. Moreover, it can be found that the pseudo-secondorder model, based on the assumption that the rate-limiting step may be chemical sorption or chemisorption involving valency forces through sharing or exchange of electrons between sorbent and sorbate, provides the better correlation of the experimental data than the pseudo-first-order model [44]. This indicates that the adsorption process may be chemisorption.

\subsubsection{Effect of $\mathrm{pH}$ on arsenate removal}

Fig. 7A shows As(V) adsorption on Fe-La composite (hydr)oxides at various $\mathrm{pH}$. It can be seen that the arsenate removal efficiency by the Fe-La composite (hydr)oxides is higher under acidic and neutral conditions compared to alkaline conditions. The removal efficiency retains almost constant under $\mathrm{pH} 7$, but dramatically declines with the increase of solution $\mathrm{pH}$ under alkaline conditions. Similar pH effect was also observed for the sorption of $\mathrm{As}(\mathrm{V})$ onto iron oxides or iron-containing oxides $[45,46]$. Low $\mathrm{pH}$ is favorable for the protonation of the sorbent 

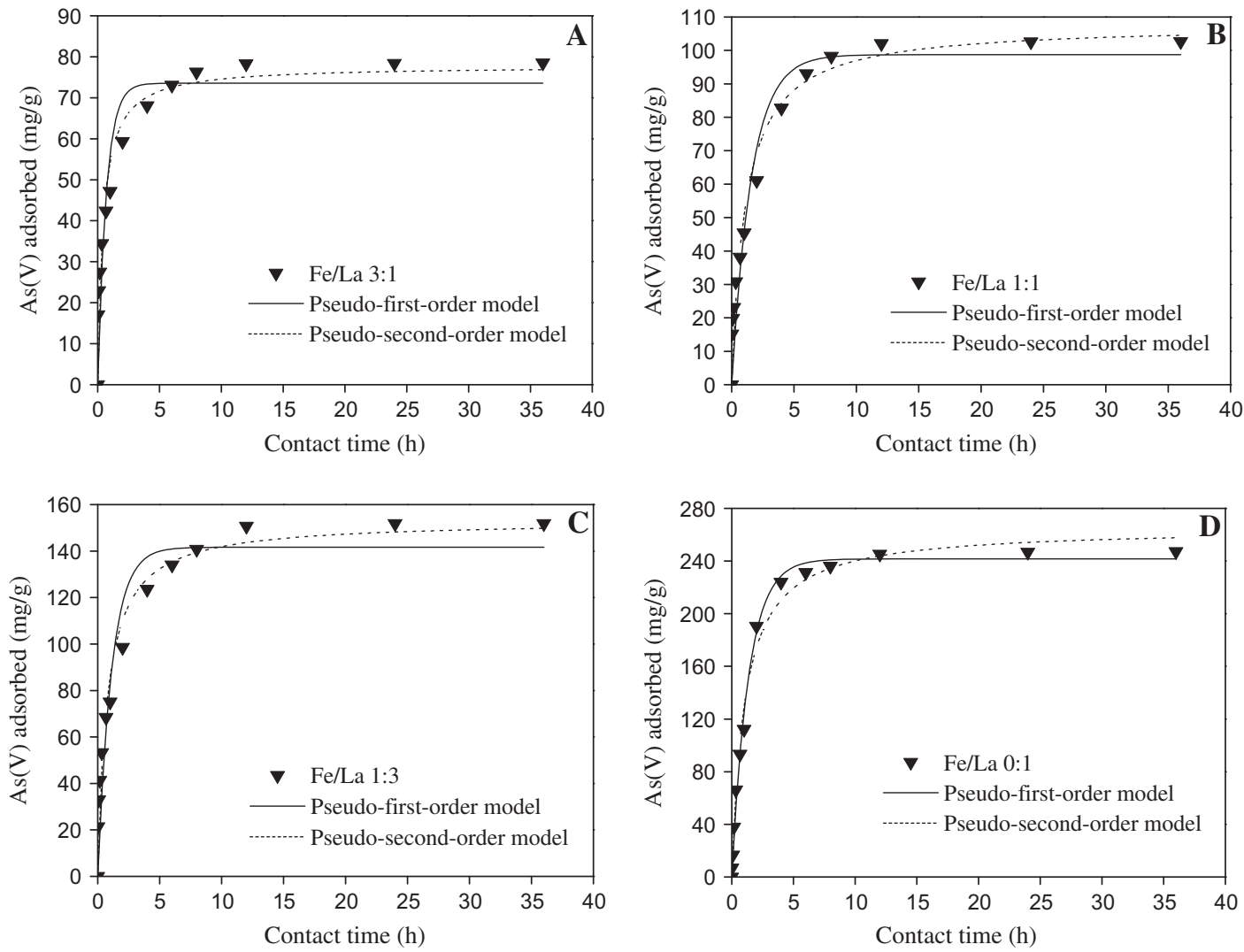

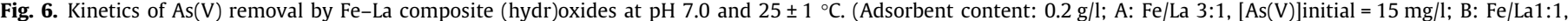
$[\mathrm{As}(\mathrm{V})]$ initial = $20 \mathrm{mg} / \mathrm{l} ; \mathrm{C}: \mathrm{Fe} / \mathrm{La} 1: 3,[\mathrm{As}(\mathrm{V})]$ initial = $30 \mathrm{mg} / \mathrm{l} ; \mathrm{D}: \mathrm{Fe} / \mathrm{La}$ 0:1, $[\mathrm{As}(\mathrm{V})]$ initial = $50 \mathrm{mg} / \mathrm{l}$.)

surface. Increased protonation is thought to increase the positively charged sites, enlarging the attraction force existing between the sorbent surface and arsenate anions. With the increase in solution $\mathrm{pH}$, the negatively charged sites gradually increase enhancing the repulsion effect, which in turn reduces the amount of adsorption. Additionally, the leaching of Fe and La from the adsorbent at different $\mathrm{pH}$ was evaluated as shown in Fig. 7B. The leaching of Fe ion from Fe-La composite (hydr)oxides was not found under different

Table 4

Adsorption rate constant obtained from pseudo-first-order model and pseudo-second-order model.

\begin{tabular}{|c|c|c|c|c|c|c|c|}
\hline \multirow[t]{2}{*}{ Adsorbent species } & \multirow[t]{2}{*}{ Initial concentration $(\mathrm{mg} / \mathrm{l})$} & \multicolumn{3}{|c|}{ Pseudo-first-order model } & \multicolumn{3}{|c|}{ Pseudo-second-order model } \\
\hline & & $k_{1}\left(\mathrm{~h}^{-1}\right)$ & $q_{e}(\mathrm{mg} / \mathrm{g})$ & $R^{2}$ & $k_{2}(\mathrm{~g} / \mathrm{mg} \mathrm{h})$ & $q_{e}(\mathrm{mg} / \mathrm{g})$ & $R^{2}$ \\
\hline Fe/La 3:1 & 15 & 1.452 & 73.6 & 0.891 & 0.03 & 77.8 & 0.945 \\
\hline $\mathrm{Fe} / \mathrm{La} 1: 1$ & 20 & 0.626 & 98.7 & 0.943 & 0.008 & 107.8 & 0.965 \\
\hline $\mathrm{Fe} / \mathrm{La} 1: 3$ & 30 & 0.881 & 141.6 & 0.923 & 0.008 & 153.0 & 0.963 \\
\hline $\mathrm{Fe} / \mathrm{La} 0: 1$ & 50 & 0.730 & 241.6 & 0.984 & 0.004 & 265.1 & 0.991 \\
\hline
\end{tabular}
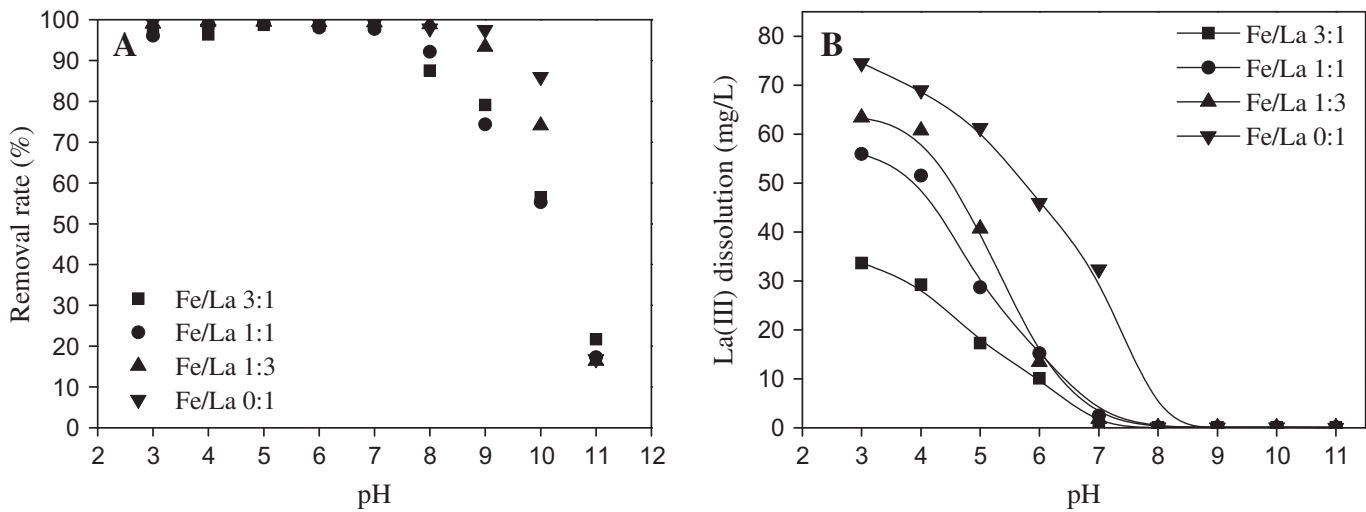

Fig. 7. (A) Percentage sorption of $\mathrm{As}(\mathrm{V})$ by Fe-La composite (hydr)oxides and (B) the leaching of $\mathrm{La}^{3+}$ ion. 


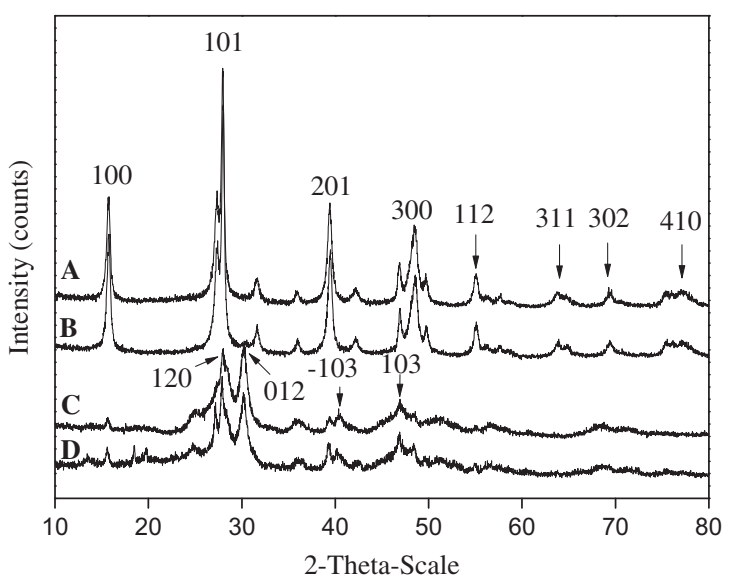

Fig. 8. XRD patterns of Fe/La 0:1 (hydr)oxide (A), after reaction with $\mathrm{As}(\mathrm{V})$ at $\mathrm{pH} 10$ (B), after reaction with $\mathrm{As}(\mathrm{V})$ at $\mathrm{pH} 7(\mathrm{C})$, and after reaction with $\mathrm{As}(\mathrm{V})$ at $\mathrm{pH} 5$ (D).

pH conditions. However, the leaching of $\mathrm{La}^{3+}$ ion occurred under acidic and neutral conditions, but decreased sharply with the increasing of solution $\mathrm{pH}$ under alkaline condition. Therefore, the leached $\mathrm{La}^{3+}$ ion from Fe-La composite (hydr)oxides may react with $\mathrm{As}(\mathrm{V})$ to form insoluble $\mathrm{LaAsO}_{4}$ precipitation under acidic and neutral conditions, because it has a rather small solubility product constant $\left(K s p=2.1 \times 10^{-23}\right)$ [47].

Based on the results above, we proposed that the $\mathrm{As}(\mathrm{V})$ removal might be accomplished through both adsorption and forming precipitation of $\mathrm{LaAsO}_{4}$ under acidic and neutral conditions, while it could be attributed only to adsorption under alkaline condition. To confirm our hypothesis, the Fe-La composite (hydr)oxides
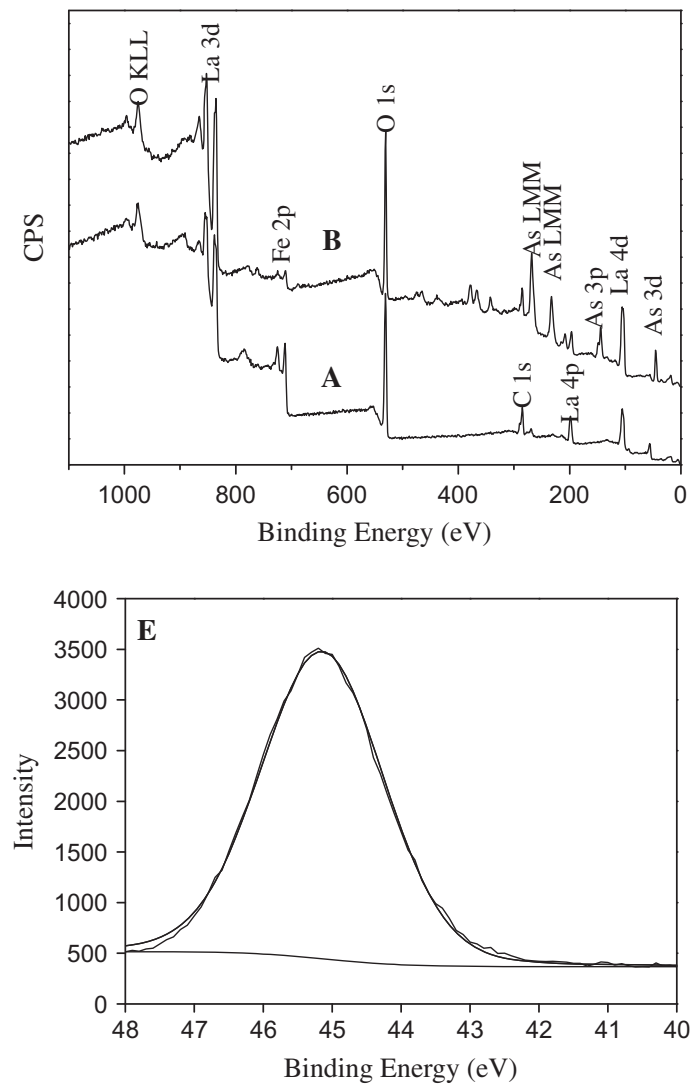

before and after reaction with arsenate were characterized by XRD, XPS and FTIR.

\subsection{Analysis of Fe-La composite (hydr)oxides before and after reaction with $A s(V)$}

\subsubsection{XRD analysis}

The XRD patterns of the Fe/La 0:1 (hydr)oxide before and after reaction with $\mathrm{As}(\mathrm{V})$ were shown in Fig. 8. The XRD patterns of Fe/La 0:1 (hydr)oxide after reaction with arsenate at $\mathrm{pH} 10.0$ had not changed, which implied that no new substance was formed and only adsorption reaction occurred. However, new peaks for (120), (012), (-103) and (103) appeared, which are the typical XRD pattern of $\mathrm{LaAsO}_{4}$ (JCPDS 15-756) [26]. This result shows that lanthanum arsenate precipitate was formed at $\mathrm{pH} 5$ and $\mathrm{pH} 7$ in the process of arsenate removal, which confirmed our above assumption.

\subsubsection{Analysis of XPS}

XPS spectra of Fe-La composite (hydr)oxides before and after reaction with arsenate were collected to verify the presence of arsenic and determine the oxidation state of adsorbed arsenic. Fig. 9(A-D) shows that the As3d core level peak as well as the AsLMM and As3p peaks have appeared after reaction with arsenate, which clearly indicates the presence of arsenate on the surface of Fe-La composite (hydr)oxides. Fig. 9(E and F) exhibits the As3d core level of 1:1 and 0:1 Fe-La composite (hydr)oxides after the adsorption of $A s(V)$. The As3d binding energies for $1: 1$ and $0: 1$ Fe-La composite (hydr)oxides were 45.3 and $45.1 \mathrm{eV}$, respectively. Previous studies reported that the binding energy of the As3d core level for $\mathrm{As}(\mathrm{V})$ in arsenic oxides is around 45.1-45.6 eV $[48,49]$. It can therefore be concluded that the arsenic species adsorbed onto
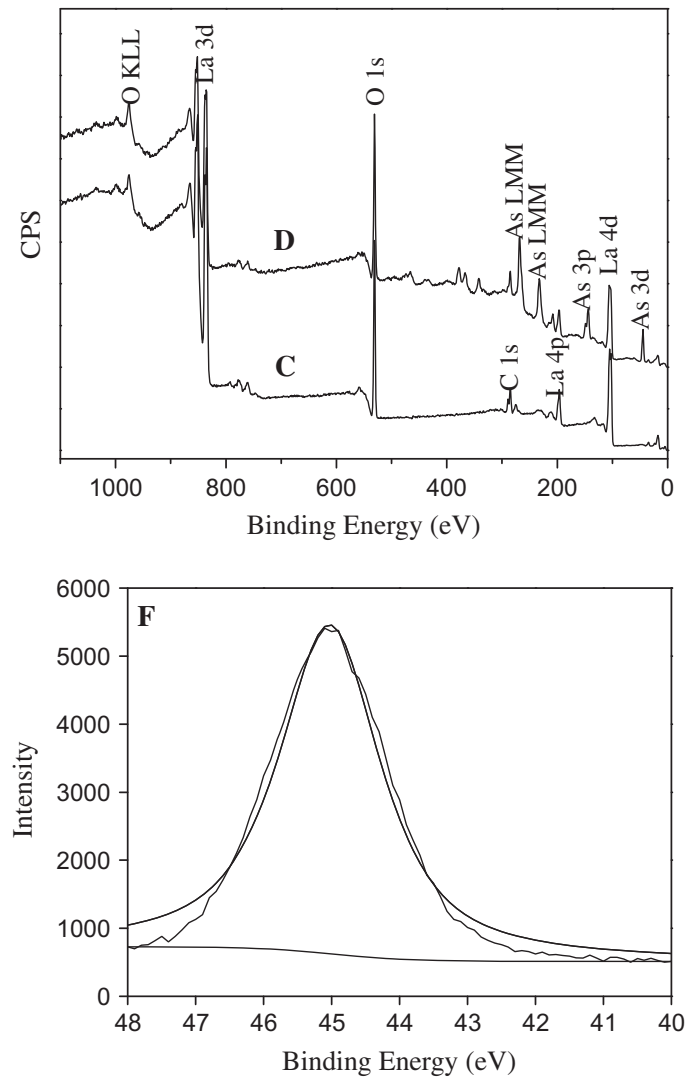

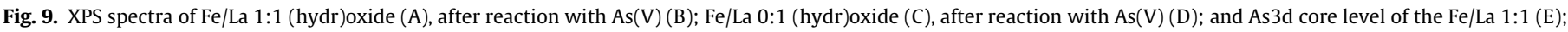
Fe/La 0:1(F) after reaction with $\mathrm{As}(\mathrm{V})$. 
the surface of Fe-La composite (hydr)oxides still remained as $\mathrm{As}(\mathrm{V})$. In other words, the oxidation state of $\mathrm{As}(\mathrm{V})$ did not change during the reaction processes.

\subsubsection{FTIR spectra}

FTIR spectra of the Fe-La composite (hydr)oxides before and after reaction with $\mathrm{As}(\mathrm{V})$ were collected and shown in Fig. 10. For the Fe/La 0:1 composite (hydr)oxide sample, the bands at $3600-3200 \mathrm{~cm}^{-1}$ are assigned to the vibration of $\mathrm{O}-\mathrm{H}$ stretching. The band at $1638 \mathrm{~cm}^{-1}$ is attributed to the deformation vibration of water molecules. These indicate the presence of physisorbed water on the oxide. The bands observed at $3609 \mathrm{~cm}^{-1}$, $1490 \mathrm{~cm}^{-1}, 1394 \mathrm{~cm}^{-1}$ and $654 \mathrm{~cm}^{-1}$ are the characteristics of the lanthanum (hydr)oxide. For the As(V)-treated sample, a new peak at $855 \mathrm{~cm}^{-1}$ appears, which may be assigned to the vibration of As-O-La groups [21]. For the Fe/La 1:1 composite (hydr)oxide, the similar phenomenon is observed. This indicates that the As $(V)$ was mainly bound as a surface complex.

\section{4. $A s(V)$ removal mechanism}

According to the above results, the mechanisms for $\mathrm{As}(\mathrm{V})$ removal by Fe-La composite (hydr)oxides were proposed. Under acidic and neutral conditions, As(V) removal was achieved by both precipitation and adsorption. However, it was mainly accomplished by adsorption under alkaline condition. The removal mechanism of arsenate by the Fe-La composite (hydr)oxides is shown in Fig. 11. Under acidic and neutral conditions, the La can be leached from $\mathrm{Fe}-\mathrm{La}$ composite (hydr)oxides and exist as $\mathrm{La}^{3+}$ in solution. In this $\mathrm{pH}$ range, arsenate ion predominantly exists as $\mathrm{H}_{2} \mathrm{AsO}_{4}^{-}$and $\mathrm{HAsO}_{4}^{2-}$ [50], reacts with $\mathrm{La}^{3+}$ ion to form insoluble lanthanum arsenate. Meanwhile, a part of $\mathrm{As}(\mathrm{V})$ is adsorbed onto the surface groups via forming bidentate binuclear (BB) and/or monodentate mononuclear (MM) complexes. Under alkaline condition, the release of La from the Fe-La composite (hydr)oxides decreases sharply and the $\mathrm{La}^{3+}$ ion entered into the solution can be negligible. Therefore, $\mathrm{As}(\mathrm{V})$ is mainly removed by adsorption onto the adsorbent surface.
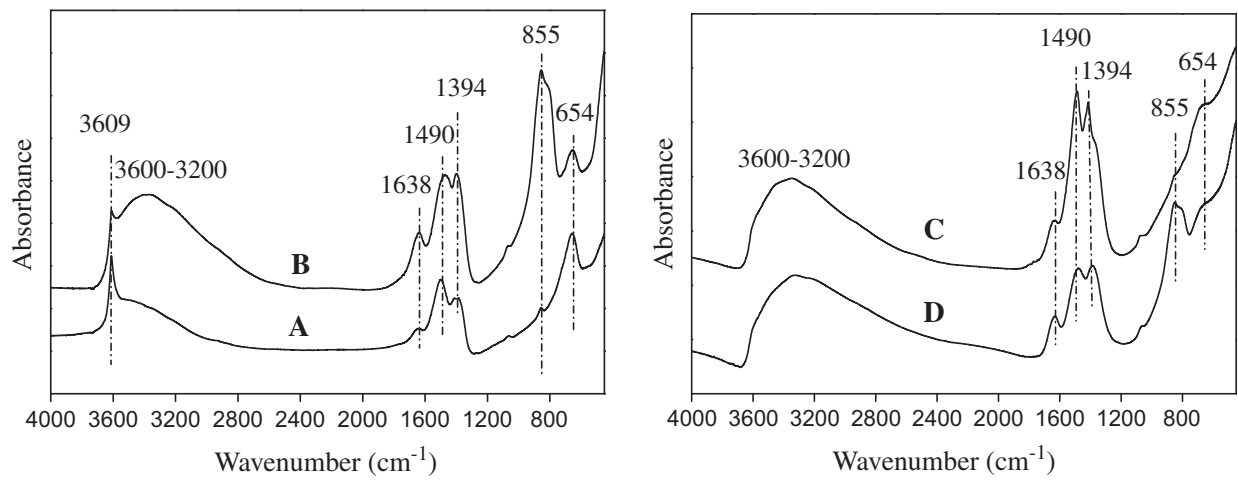

Fig. 10. FTIR spectra of Fe/La 0:1 (hydr)oxide (A), after reaction with $\mathrm{As}(\mathrm{V})(\mathrm{B})$; and Fe/La 1:1 (hydr)oxide (C), after reaction with $\mathrm{As}(\mathrm{V})(\mathrm{D})$.

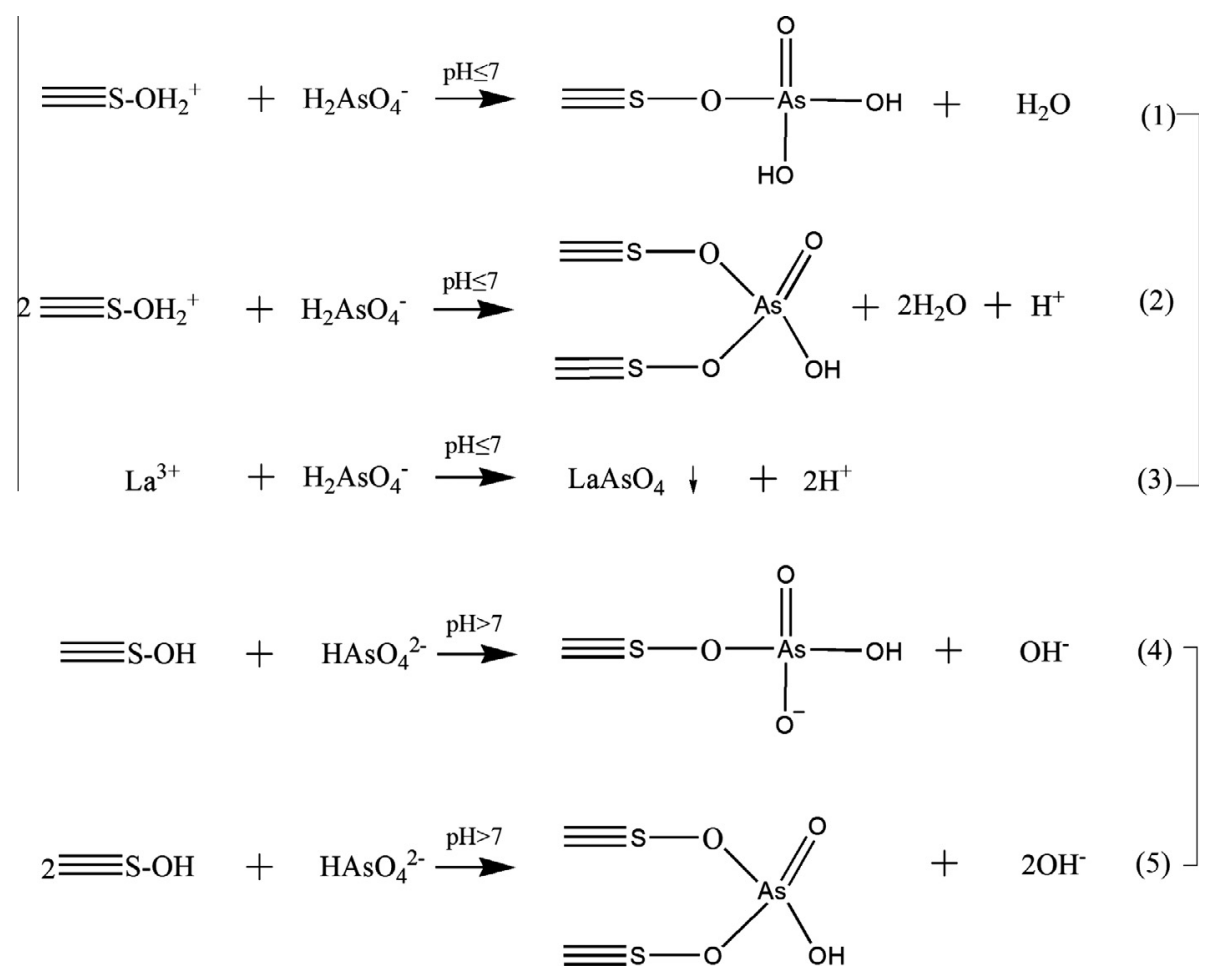

Fig. 11. Schematic diagram of $\mathrm{As}(\mathrm{V})$ removal mechanism. 


\subsection{Regeneration and reusability of the Fe/La 1:1 composite (hydr)oxide}

To assess the reusability of the used Fe/La 1:1 composite (hydr)oxide, its regeneration using $\mathrm{NaOH}$ solution and re-adsorption were investigated. These adsorption-regeneration cycles were carried out up to four times and the results were demonstrated in SI Fig. 2. The value of cycle 0 corresponds to the adsorption capacity of the fresh Fe/La 1:1 composite (hydr)oxide. The As(V) adsorption capacity of the Fe/La 1:1 composite (hydr)oxide slowly decreased with an increase in regeneration cycle. Whereas, this reduction was not so remarkable and about $75 \%$ of the original adsorption capacity was still achieved after 4 times regeneration. These indicate that the adsorption of $\mathrm{As}(\mathrm{V})$ on $\mathrm{Fe}-\mathrm{La}$ composite (hydr)oxides are relatively reversible and spent $\mathrm{Fe}$-La composite (hydr)oxides could be effectively regenerated via $\mathrm{NaOH}$ treatment.

\section{Conclusions}

In this study, a series of Fe-La composite (hydr)oxides were synthesized by coprecipitation method for arsenate removal from aqueous solutions. The as-prepared Fe-La composite (hydr)oxides grains were formed by nanoparticles or nanoflakes. With an increase in La content, the specific surface area of Fe-La composite (hydr)oxides decreased, but the pore diameter, the pore volume and the grain size of Fe-La composite (hydr)oxides increased gradually. The pseudo-second-order equation and Langmuir adsorption model fitted the adsorption data. The calculated Langmuir adsorption capacities of 3:1, 1:1, 1:3 and 0:1 Fe-La composite (hydr)oxides were $116 \mathrm{mg} / \mathrm{g}, 166 \mathrm{mg} / \mathrm{g}, 235 \mathrm{mg} / \mathrm{g}$ and $368 \mathrm{mg} / \mathrm{g}$ at $\mathrm{pH} 7.0$, respectively. In addition, the Fe-La composite (hydr)oxides were effective for $\mathrm{As}(\mathrm{V})$ removal across a wide $\mathrm{pH}$ range. Under acidic and neutral conditions, precipitation and adsorption were the main mechanisms of $\mathrm{As}(\mathrm{V})$ removal, while only adsorption contributed to $\mathrm{As}(\mathrm{V})$ removal under alkaline condition. The spent Fe-La composite (hydr)oxide could be effectively regenerated using $\mathrm{NaOH}$ solution and reused several times. The high removal efficiency of the Fe-La composite (hydro)oxide makes it attractive adsorbent for treatment of water contaminated with $\mathrm{As}(\mathrm{V})$.

\section{Acknowledgements}

The authors acknowledge financial support by National Natural Science Foundation of China (Grant Nos. 51178453 and 51328803). Xiwang Zhang thanks Australia Research Council and Monash University for his ARF (DP110103533) and Larkins Fellowships.

\section{Appendix A. Supplementary material}

Supplementary data associated with this article can be found, in the online version, at http://dx.doi.org/10.1016/j.cej.2014.04.057.

\section{References}

[1] P. Smedley, D. Kinniburgh, A review of the source, behaviour and distribution of arsenic in natural waters, Appl. Geochem. 17 (2002) 517-568.

[2] B.K. Mandal, K.T. Suzuki, Arsenic round the world: a review, Talanta 58 (2002) 201-235.

[3] J. Matschullat, Arsenic in the geosphere - a review, Sci. Total Environ. 249 (2000) 297-312.

[4] J.C. Ng, J. Wang, A. Shraim, A global health problem caused by arsenic from natural sources, Chemosphere 52 (2003) 1353-1359.

[5] T.S.Y. Choong, T.G. Chuah, Y. Robiah, F.L.G. Koay, I. Azni, Arsenic toxicity, health hazards and removal techniques from water: an overview, Desalination 217 (2007) 139-166.

[6] T.R. Holm, Effects of $\mathrm{CO}_{3}^{2-}$ /bicarbonate, $\mathrm{Si}$, and $\mathrm{PO}_{4}^{3-}$ on arsenic sorption to HFO, J. Am. Water Works Assoc. 94 (2002) 174-181.

[7] J.Q. Jiang, Removing arsenic from groundwater for the developing world-a review, Water Sci. Technol. 44 (2001) 89-98.
[8] K. Wu, R. Liu, T. Li, J. Peng, Removal of arsenic (III) from aqueous solution using a low-cost by-product in Fe-removal plants-Fe-based backwashing sludge, Chem. Eng. J. 226 (2013) 393-401.

[9] Y. Glocheux, M.M. Pasarín, A.B. Albadarin, S.J. Allena, M.W. Gavin, Removal of arsenic from groundwater by adsorption onto an acidified laterite by-product, Chem. Eng. J. 228 (2013) 565-574.

[10] M.L. Pierce, C.B. Moore, Adsorption of arsenite and arsenate on amorphous iron hydroxide, Water Res. 16 (1982) 1247-1253.

[11] S. Dixit, J.G. Hering, Comparison of arsenic (V) and arsenic (III) sorption onto iron oxide minerals: implications for arsenic mobility, Environ. Sci. Technol. 37 (2003) 4182-4189.

[12] X. Luo, C. Wang, S. Luo, R. Dong, X. Tua, G. Zeng, Adsorption of As (III) and As (V) from water using magnetite $\mathrm{Fe}_{3} \mathrm{O}_{4}$-reduced graphite oxide- $\mathrm{MnO}_{2}$ nanocomposites, Chem. Eng. J. 187 (2012) 45-52.

[13] Y. Zhang, M. Yang, X. Huang, Arsenic (V) removal with a Ce (IV)-doped iron oxide adsorbent, Chemosphere 51 (2003) 945-952.

[14] G. Zhang, J. Qu, H. Liu, R. Liu, R. Wu, Preparation and evaluation of a novel FeMn binary oxide adsorbent for effective arsenite removal, Water Res. 41 (2007) 1921-1928.

[15] Y. Masue, R.H. Loeppert, T.A. Kramer, Arsenate and arsenite adsorption and desorption behavior on coprecipitated aluminum: iron hydroxides, Environ. Sci. Technol. 41 (2007) 837-842.

[16] K. Gupta, K. Biswas, U.C. Ghosh, Nanostructure iron (III)-zirconium (IV) binary mixed oxide: synthesis, characterization, and physicochemical aspects of arsenic (III) sorption from the aqueous solution, Ind. Eng. Chem. Res. 47 (2008) 9903-9912.

[17] G. Zhang, Z. Ren, X. Zhang, J. Chen, Nanostructured iron (III)-copper (II) binary oxide: a novel adsorbent for enhanced arsenic removal from aqueous solutions, Water Res. 47 (2013) 4022-4031.

[18] K. Gupta, U.C. Ghosh, Arsenic removal using hydrous nanostructure iron (III)titanium (IV) binary mixed oxide from aqueous solution, J. Hazard. Mater. 161 (2) (2009) 884-892.

[19] S. Tokunaga, S.A. Wasay, S.-W. Park, Removal of arsenic (V) ion from aqueous solutions by lanthanum compounds, Water Sci. Technol. 35 (1997) 71-78.

[20] S. Wasay, M. Haran, S. Tokunaga, Adsorption of fluoride, phosphate, and arsenate ions on lanthanum-impregnated silica gel, Water Environ. Res. 68 (1996) 295-300.

[21] M. Jang, J.K. Park, E.W. Shin, Lanthanum functionalized highly ordered mesoporous media: implications of arsenate removal, Micropor. Mesopor. Mater. 75 (2004) 159-168.

[22] H. Pu, J. Huang, Z. Jiang, Removal of arsenic (V) from aqueous solutions by lanthanum-loaded zeolite, Acta Geol. Sin. - Engl. 82 (2008) 1015-1019.

[23] Y. Guo, Z. Zhu, Y. Qiu, J. Zhao, Adsorption of arsenate on $\mathrm{Cu} / \mathrm{Mg} / \mathrm{Fe} / \mathrm{La}$ layered double hydroxide from aqueous solutions, J. Hazard. Mater. 239 (2012) 279288 .

[24] D. Kinniburgh, J. Syers, M. Jackson, Specific adsorption of trace amounts of calcium and strontium by hydrous oxides of iron and aluminum, Soil Sci. Soc. Am. J. 39 (1975) 464-470.

[25] G. Wu, X. Wang, B. Chen, J. Li, N. Zhao, W. Wei, Y. Sun, Fluorine-modified mesoporous $\mathrm{Mg}-\mathrm{Al}$ mixed oxides: mild and stable base catalysts for Omethylation of phenol with dimethyl carbonate, Appl. Catal. A 329 (2007) 106-111.

[26] A. Hofmann, M. Pelletier, L. Michot, A. Stradner, P. Schurtenberger, R. Kretzschmar, Characterization of the pores in hydrous ferric oxide aggregates formed by freezing and thawing, J. Colloid Interface Sci. 271 (2004) 163-173.

[27] P. Diffract, File, JCPDS Internet, Centre Diffract. Data, PA, 19073, 2004.

[28] I. Langmuir, The constitution and fundamental properties of solids and liquids. Part I. Solids, J. Am. Chem. Soc. 38 (1916) 2221-2295.

[29] H. Freundlich, Über die adsorption in lösungen, Z. Phys. Chem. A 57 (1906) $385-470$.

[30] M. Haron, W.W. Yunus, M. Sukari, S. Tokunaga, S. Wasay, Removal of arsenic (V) ion from aqueous solutions by basic lanthanum carbonate, Malay. J. Anal. Sci. 7 (2001) 173-176.

[31] Z. Ren, G. Zhang, J.P. Chen, Adsorptive removal of arsenic from water by an iron-zirconium binary oxide adsorbent, J. Colloid Interface Sci. 358 (2011) 230-237.

[32] J. Hlavay, K. Polyák, Determination of surface properties of iron hydroxidecoated alumina adsorbent prepared for removal of arsenic from drinking water, J. Colloid Interface Sci. 284 (2005) 71-77.

[33] K. Gupta, U.C. Ghosh, Arsenic removal using hydrous nanostructure iron (III)titanium (IV) binary mixed oxide from aqueous solution, J. Hazard. Mater. 161 (2009) 884-892.

[34] B.R. Manna, S. Dey, S. Debnath, U.C. Ghosh, Removal of arsenic from groundwater using crystalline hydrous ferric oxide (CHFO), Water Qual. Res. J. Can. 38 (2003) 193-210.

[35] M.E. Pena, G.P. Korfiatis, M. Patel, L. Lippincott, X.G. Meng, Adsorption of As(V) and $\mathrm{As}(\mathrm{III})$ by nanocrystalline titanium dioxide, Water Res. 39 (2005) 2327 2337.

[36] C. Jing, X. Meng, S. Liu, S. Baidas, R. Patraju, C. Christodoulatos, G.P. Korfiatis, Surface complexation of organic arsenic on nanocrystalline titanium oxide, J. Colloid Interface Sci. 290 (2005) 14-21.

[37] B. Manna, U.C. Ghosh, Adsorption of arsenic from aqueous solution on synthetic hydrous stannic oxide, J. Hazard. Mater. 144 (2007) 522-531.

[38] E. Deliyanni, D. Bakoyannakis, A. Zouboulis, K. Matis, Sorption of As (V) ions by akaganeite-type nanocrystals, Chemosphere 50 (2003) 155-163. 
[39] L.A. Rodrigues, M.L.C.P. da Silva, Thermodynamic and kinetic investigations of phosphate adsorption onto hydrous niobium oxide prepared by homogeneous solution method, Desalination 263 (2010) 29-35.

[40] B.H. Hameed, A.A. Ahmad, N. Aziz, Isotherms, kinetics and thermodynamics of acid dye adsorption on activated palm ash, Chem. Eng. J. 133 (2007) 195-203.

[41] E.I. Unuabonah, K.O. Adebowale, B.I. Olu-Owolabi, Kinetic and thermodynamic studies of the adsorption of lead (II) ions onto phosphate-modified kaolinite clay, J. Hazard. Mater. 144 (2007) 386-395.

[42] H. Nollet, M. Roels, P. Lutgen, P.V. der Meeren, W. Verstraete, Removal of PCBs from wastewater using fly ash, Chemosphere 53 (2003) 655-665.

[43] S. Lagergren, About the theory of so-called adsorption of soluble substances, Handlingar, Band 24 (1898) 1-39.

[44] Y. Ho, G. McKay, Kinetic model for lead (II) sorption on to peat, Adsorpt. Sci. Technol. 16 (1998) 243-255.
[45] F. Kingston, A. Posner, J.P. QUIRK, Anion adsorption by goethite and gibbsite, J. Soil Sci. 23 (1972) 177-192.

[46] G. Zhang, H. Liu, R. Liu, J. Qu, Removal of phosphate from water by a Fe-Mn binary oxide adsorbent, J. Colloid Interface Sci. 335 (2009) 168-174.

[47] N.C. Norman, Chemistry of Arsenic, Antimony and Bismuth, Blackie Academic and Professional, New York, 1998.

[48] H. Nesbitt, G. Canning, G. Bancroft, XPS study of reductive dissolution of $7 \AA$ birnessite by $\mathrm{H}_{3} \mathrm{AsO}_{3}$, with constraints on reaction mechanism, Geochim. Cosmochim. Acta 62 (1998) 2097-2110.

[49] S. Ouvrard, P. De Donato, M. Simonnot, S. Begin, J. Ghanbaja, M. Alnot, Y. Duval, F. Lhote, O. Barres, M. Sardin, Natural manganese oxide: combined analytical approach for solid characterization and arsenic retention, Geochim. Cosmochim. Acta 69 (2005) 2715-2724.

[50] R.M. Smith, A.E. Martell, Critical Stability Constants - Inorganic Complexes, vol. 4, Plenum Press, New York, 1976. 